The following resources related to this article are available online at www.sciencemag.org (this information is current as of October 14, 2009 ):

Updated information and services, including high-resolution figures, can be found in the online version of this article at:

http://www.sciencemag.org/cgi/content/full/326/5949/69

Supporting Online Material can be found at:

http://www.sciencemag.org/cgi/content/full/326/5949/69/DC1

A list of selected additional articles on the Science Web sites related to this article can be found at:

http://www.sciencemag.org/cgi/content/full/326/5949/69\#related-content

This article cites 37 articles, 2 of which can be accessed for free:

http://www.sciencemag.org/cgi/content/full/326/5949/69\#otherarticles

This article has been cited by 4 articles hosted by HighWire Press; see:

http://www.sciencemag.org/cgi/content/full/326/5949/69\#otherarticles

This article appears in the following subject collections:

Anthropology

http://www.sciencemag.org/cgi/collection/anthro

Information about obtaining reprints of this article or about obtaining permission to reproduce this article in whole or in part can be found at:

http://www.sciencemag.org/about/permissions.dtl 


\title{
Paleobiological Implications of the Ardipithecus ramidus Dentition
}

\author{
Gen Suwa, Reiko T. Kono, Scott W. Simpson, Berhane Asfaw, C. Owen Lovejoy, Tim D. White
}

$\mathrm{T}$ eeth are highly resilient to degradation and therefore are the most abundant specimens in the primate fossil record. The size, shape, enamel thickness, and isotopic composition of teeth provide a wealth of information about phylogeny, diet, and social behavior. Ardipithecus ramidus was originally defined in 1994 primarily on the basis of recovered teeth, but the sample size was small, limiting comparison to other primate fossils. We now have over 145 teeth, including canines from up to 21 individuals. The expanded sample now provides new information regarding Ar. ramidus and, using comparisons with teeth of other hominids, extant apes, and monkeys, new perspectives on early hominid evolution as well.

In apes and monkeys, the male's upper canine tooth usually bears a projecting, daggerlike crown that is continuously sharpened (honed) by wear against a specialized lower premolar tooth (together these form the $\mathrm{C} / \mathrm{P}_{3}$ complex). The canine tooth is used as a slicing weapon in intra- and intergroup social conflicts. Modern humans have small, stublike canines which

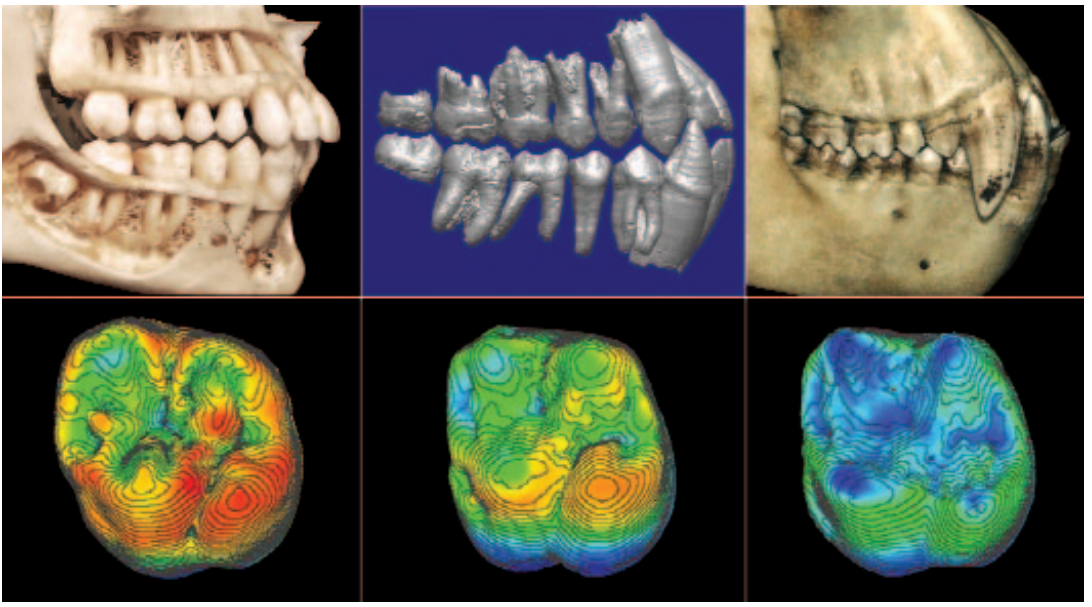

Dentitions from human (left), Ar. ramidus (middle), and chimpanzee (right), all males. Below are corresponding samples of the maxillary first molar in each. Red, thicker enamel $(\sim 2 \mathrm{~mm})$; blue, thinner enamel $(\sim 0.5 \mathrm{~mm})$. Contour lines map the topography of the crown and chewing surfaces. function more like incisors.

All known modern and fossil apes have (or had) a honing $\mathrm{C} / \mathrm{P}_{3}$ complex. In most species, this is more developed in males than females (in a few species, females have male-like large canines, either for territorial defense or for specialized feeding). The relatively large number of Ar. ramidus teeth, in combination with Ethiopian Ar. kadabba, Kenyan Orrorin, and Chadian Sahelanthropus [currently the earliest known hominids at about 6 million years ago (Ma)], provide insight into the ancestral ape $\mathrm{C} / \mathrm{P}_{3}$ complex and its evolution in early hominids.

In basal dimensions, the canines of Ar. ramidus are roughly as large as those of female chimpanzees and male bonobos, but their crown heights are shorter (see figure). The Ar. ramidus sample is now large enough to assure us that males are represented. This means that male and female canines were not only similar in size, but that the male canine had been dramatically "feminized" in shape. The crown of the upper canine in Ar. ramidus was altered from the pointed shape seen in apes to a less-threatening diamond shape in both males and females. There is no evidence of honing. The lower canines of $A r$. ramidus are less modified from the inferred female ape condition than the uppers. The hominid canines from about $6 \mathrm{Ma}$ are similar in size to those of $A r$ ramidus, but (especially) the older upper canines appear slightly more primitive. This suggests that male canine size and prominence were dramatically reduced by $\sim 6$ to $4.4 \mathrm{Ma}$ from an ancestral ape with a honing $\mathrm{C} / \mathrm{P}_{3}$ complex and a moderate degree of male and female canine size difference.
In modern monkeys and apes, the upper canine is important in male agonistic behavior, so its subdued shape in early hominids and Ar. ramidus suggests that sexual selection played a primary role in canine reduction. Thus, fundamental reproductive and social behavioral changes probably occurred in hominids long before they had enlarged brains and began to use stone tools.

Thick enamel suggests that an animal's food intake was abrasive; for example, from terrestrial feeding. Thin enamel is consistent with a diet of softer and less abrasive foods, such as arboreal ripe fruits. We measured the enamel properties of more than $30 \mathrm{Ar}$. ramidus teeth. Its molar enamel is intermediate in thickness between that of chimpanzees and Australopithecus or Homo. Chimpanzees have thin enamel at the chewing surface of their molars, whereas a broad concave basin flanked by spiky cusps facilitates crushing fruits and shredding leaves. Ar. ramidus does not share this pattern, implying a diet different from that of chimpanzees. Lack of thick enamel indicates that $A r$ ramidus was not as adapted to heavy chewing and/or eating abrasive foods as were later Australopithecus or even Homo. The combined evidence from the isotopic content of the enamel, dental wear, and molar structure indicates that the earliest hominid diet was one of generalized omnivory and frugivory and therefore differed from that of Australopithecus and living African apes.

When citing, please refer to the full paper, available at DOI 10.1126/science.1175824. 


\section{Paleobiological Implications of the Ardipithecus ramidus Dentition}

\author{
Gen Suwa, ${ }^{1}$ Reiko T. Kono, ${ }^{2}$ Scott W. Simpson, ${ }^{3}$ Berhane Asfaw, ${ }^{4}$ \\ C. Owen Lovejoy, ${ }^{5}$ Tim D. White ${ }^{6}$
}

The Middle Awash Ardipithecus ramidus sample comprises over 145 teeth, including associated maxillary and mandibular sets. These help reveal the earliest stages of human evolution. Ar. ramidus lacks the postcanine megadontia of Australopithecus. Its molars have thinner enamel and are functionally less durable than those of Australopithecus but lack the derived Pan pattern of thin occlusal enamel associated with ripe-fruit frugivory. The Ar. ramidus dental morphology and wear pattern are consistent with a partially terrestrial, omnivorous/frugivorous niche. Analyses show that the ARA-VP-6/500 skeleton is female and that Ar. ramidus was nearly monomorphic in canine size and shape. The canine/lower third premolar complex indicates a reduction of canine size and honing capacity early in hominid evolution, possibly driven by selection targeted on the male upper canine.

$\mathrm{F}$ ossilized teeth typically represent the most abundant and best preserved remains of hominids and other primates. They provide crucial evidence on variation, phylogenetic relationships, development, and dietary adaptations. Furthermore, because canines function as weapons in interindividual aggression in most anthropoid species, they additionally inform aspects of social structure and behavior.

We have now recovered and analyzed a sample of 145 non-antimeric tooth crowns comprising 62 cataloged dentition-bearing specimens of Ardipithecus ramidus from the Lower Aramis Member of the Sagantole Formation, about five times more than previously reported $(1,2)$ (Fig. 1 and table S1). All permanent tooth positions are represented, with a minimum of 14 individuals for both the upper canine and upper second molar $\left(\mathrm{M}^{2}\right)$ positions. Excluding antimeres, 101 teeth have measurable crown diameters. In addition, seven Ar. ramidus specimens with teeth have been described from Gona (3). These are broadly comparable to their Aramis counterparts in size, proportions, and morphology but slightly extend the smaller end of the species range in some mandibular crown diameters.

The major morphological characteristics of the Ar. ramidus dentition have been outlined in previous studies of Aramis and Gona fos-

\footnotetext{
${ }^{1}$ The University Museum, the University of Tokyo, Hongo, Bunkyo-ku, Tokyo, 113-0033 Japan. ${ }^{2}$ Department of Anthropology, National Museum of Nature and Science, Hyakunincho, Shinjuku-ku, Tokyo, 169-0073 Japan. ${ }^{3}$ Department of Anatomy, Case Western Reserve University School of Medicine, Cleveland, OH 44106-4930, USA. ${ }^{4}$ Rift Valley Research Service, Post Office Box 5717, Addis Ababa, Ethiopia. ${ }^{5}$ Department of Anthropology, Division of Biomedical Sciences, Kent State University, Kent, OH 44240-0001, USA. ${ }^{6}$ Human Evolution Research Center and Department of Integrative Biology, 3101 VLSB, University of California Berkeley, Berkeley, CA 94720, USA.
}

${ }^{*}$ To whom correspondence should be addressed. E-mail: suwa@um.u-tokyo.ac.jp sils $(1,3,4)$. Comparisons of Ar. ramidus with Late Miocene hominids (Ar. kadabba, Orrorin tugenensis, and Sahelanthropus tchadensis) have identified slight but distinct differences, particularly in the canine (4-6). Other subtle features of incisors and postcanine teeth have been noted as phylogenetic or taxonomic distinctions $(5-10)$. However, the most recent and comprehensive evaluation of the available Late Miocene materials concluded that these differences are minor compared with extant ape (and later hominid) genus-level variation and that both Ar. ramidus and $A r$. kadabba dentitions exhibit phenetic similarities with early Australopithecus (4).

The expanded Ar. ramidus sample of the present study allows a more definitive phylogenetic placement of Ar. ramidus relative to the more primitive Ar. kadabba and the more derived $A u$. anamensis and Au. afarensis (11). Here, we focus on the paleobiological aspects of the $A r$. ramidus dentition, including variation, size, and scaling, probable dietary niche, and canine/lower third premolar $\left(\mathrm{C} / \mathrm{P}_{3}\right)$ complex evolution and its behavioral implications. We also address the alleged phylogenetic importance (7) of enamel thickness in Ar. ramidus (1). This is now made possible by the more comprehensive dental collection that includes key associated dental sets.

Crown size, proportions, and variation. The Ar. ramidus dentition is approximately chimpanzee-sized (fig. S1 and tables S2 to S4). Mean canine size is comparable to that of female Pan troglodytes, although the incisors are smaller. Upper and lower first molars (M1s) are $P$. troglodytes-sized but tend to be buccolingually broader (figs. S1 to S3). The second and third molars (M2s and M3s) are both absolutely and relatively larger (figs. S1 and S4 to S6). Postcanine size and proportions of Ar. ramidus are similar to those of $A r$. kadabba and other $\sim 6.0$-million-year-old forms (O. tugenensis and S. tchadensis) (4-10), as well as to many Mio- cene hominoids (although Miocene ape lower molars tend to be buccolingually narrower) (fig. S3).

Variation within the Aramis dental sample is low. In modern anthropoids, the coefficient of variation (CV) is lowest in M1 and M2, with single-sex and mixed-sex values usually ranging from about 3.5 to 6.5 (12-14). At Aramis, Ar. ramidus upper and lower M1s and M2s are less variable (CVs ranging from 2.5 to 5.6) than those of Australopithecus afarensis and Au. anamensis (table S2). However, these Australopithecus samples represent multiple sites and span a much greater time than the Aramis fossils (11). The low variation seen in Aramis $A r$. ramidus probably reflects spatially and temporally restricted sampling and low postcanine sexual dimorphism as in Pan (15) (table S5).

The Aramis postcanine dentition is also morphologically more homogenous than known Australopithecus species samples. For example, the six relatively well-preserved $\mathrm{M}^{1} \mathrm{~s}$ (Fig. 1) differ little in features otherwise known to vary widely within hominid and modern hominoid species $(16,17)$, including Carabelli's expression, occlusal crest development, and hypocone lingual bulge. This suggests that the Aramis $A r$. ramidus collection samples regional demes or local populations with persistent idiosyncratic tendencies. The ubiquitous occurrence of single rooted lower fourth premolars $\left(\mathrm{P}_{4}\right)$ (now seen in eight non-antimeric Aramis $\mathrm{P}_{4} \mathrm{~s}$ ) suggests increased frequency of otherwise rare variants from genetic drift, absent substantial selection for larger and/or more complicated root systems (18). Because this anatomy is shared with Gona Ar. ramidus (3), it appears characteristic of this regional population.

Morphology and evolution of the $C / \mathrm{P}_{3}$ complex. The $\mathrm{C} / \mathrm{P}_{3}$ complex of anthropoids has behavioral and evolutionary importance because canine size and function are directly linked to male reproductive success (19). Therefore, clarifying the tempo and mode of the evolution of the $\mathrm{C} / \mathrm{P}_{3}$ complex, from hominid emergence through its early evolution, is important.

Not counting antimeres, 23 upper and lower canines from $21 \mathrm{Ar}$. ramidus individuals are now known from Aramis. Three more have been described from Gona (3), and seven from the $\sim 6.0$ million-year-old Ar. kadabba, O. tugenensis, and S. tchadensis (4-10). There are no examples of a distinctly large male morphotype in any of these collections (Fig. 1 and figs. S7 and S8), suggesting that canine sexual dimorphism was minimal in Mio-Pliocene hominids. In basal crown dimensions, Ar. ramidus canine/postcanine size ratios overlap extensively with those of modern and Miocene female apes (fig. S9). Absolute and relative canine heights are also comparable to those of modern female apes, although canine height appears exaggerated in $P$. troglodytes [Fig. 1; figs. S8, S10, and S11; and supporting online material (SOM) text $\mathrm{S} 1]$. 
Canine shape of Ar. ramidus is either comparable to female apes or more derived toward Australopithecus (11) (Fig. 1 and figs. S12 and
S13). The upper canine (UC) is clearly derived in Ar. ramidus, because it has a diamond-shaped lateral crown profile with elevated and/or flar-
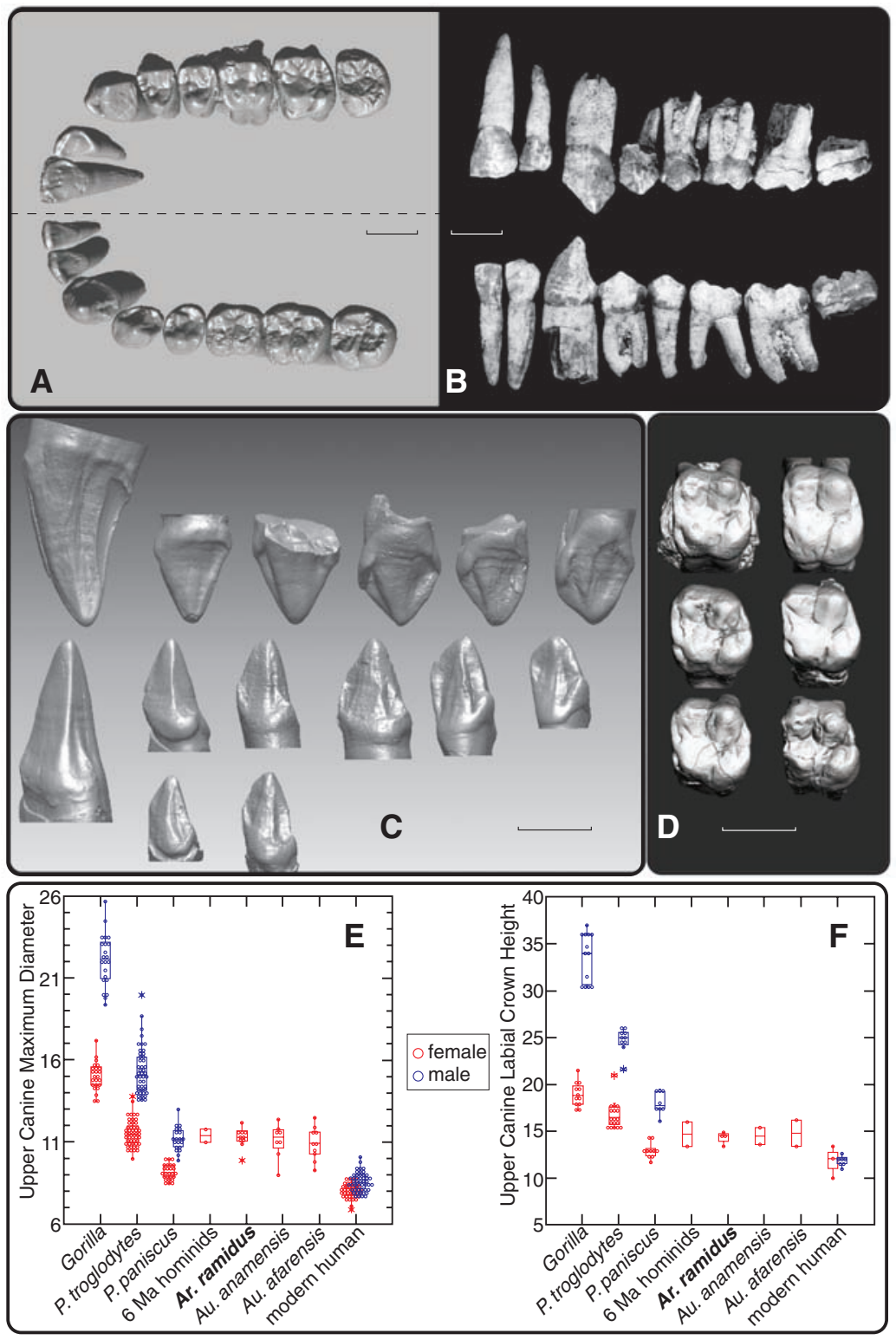

Fig. 1. Representative examples of the Aramis Ardipithecus ramidus dentition. (A) Occlusal view micro-CTbased alignment of $A R A-V P-1 / 300$ : top, maxillary dentition; bottom, mandibular dentition. The betterpreserved side was scanned and mirror-imaged to form these composites. (B) ARA-VP-1/300 in buccal view: top, right maxillary dentition (mirrored); bottom, left mandibular dentition. (C) Comparison of canine morphology (micro-CT-based renderings). Top row, lingual view of upper canines, from left to right: male $P$. troglodytes (cast), female $P$. troglodytes (cast), Ar. kadabba ASK-VP-3/400, Ar. ramidus ARA-VP-6/1, Au. afarensis L.H. 6 (cast), Au. afarensis A.L. 333x-3 (cast, mirrored). Lower rows, distolingual view of lower canines, main row from left to right: male $P$. troglodytes (cast), female $P$. troglodytes (cast), Ar. kadabba (STD-VP-2/61), Ar. ramidus ARA-VP-1/300, Au. africanus Sts 50 (mirrored), Au. africanus Sts 51. Lowest two specimens are ape lower canines with hominid-like features: left, P. paniscus (cast); right, Ouranopithecus macedoniensis RLP-55 (cast). The Ar. ramidus upper canine is highly derived, with a diamond-shaped crown with elevated crown shoulders. The lower canine tends to retain aspects of primitive ape features. Further details are given in the SOM figures and SOM text S1. (D) $M^{1}$ morphology (micro-CT-based renderings) showing relatively little morphological variation among the Aramis individuals. Top row left, $A R A-V P-1 / 300$ (mirrored); right, ARA-VP-1/1818. Middle row left, ARA-VP-1/3288; right, ARA-VP-6/500. Bottom row left, ARA-VP-6/502 (mirrored); right, KUS-VP-2/154. (E and F) Box plot of upper canine maximum diameter and labial height (in $\mathrm{mm})$. Ar. ramidus includes Aramis and published Gona materials (2). The $\sim 6$-million-year-old hominids are represented by Ar. kadabba (ASK-VP-3/400) and O. tugenensis (BAR 1425'00) (7). Symbols give central 50\% range (box), range (vertical line) and outliers. See SOM figures and text S1 for additional plots and details.

ing crown shoulders ( $n=5$ from Aramis and $n=1$ from Gona) [this study and $(3,4,6)$ ]. However, the lower canine (LC) retained much more of the morphology of the female ape condition $(4,5)$ (Fig. 1, figs. S11 to S13, and SOM text S1). A hominid-like incisiform LC morphology (high mesial shoulder, developed distal crest terminating at a distinct distal tubercle) is seen in some female apes (e.g., Ouranopithecus and P. paniscus), whereas the LCs of Ar. kadabba and Ar. ramidus tend to be conservative, exhibiting a strong distolingual ridge and faint distal crest, typical of the interlocking ape $\mathrm{C} / \mathrm{P}_{3}$ complex (4) (Fig. 1 and SOM text S1).

The Ar ramidus $\mathrm{P}_{3}$ is represented by seven observable crowns, ranging from obliquely elongate to transversely broad (1) (fig. S14). The Ar. ramidus $\mathrm{P}_{3}$ is relatively smaller than that of Pan and typically not as asymmetric or elongate in occlusal view (figs. S15 and S16). In these respects, the Ar. ramidus $\mathrm{P}_{3}$ is comparable to those of $A u$. anamensis and $A u$. afarensis. However, $A r$. ramidus is more primitive than Australopithecus in retaining a proportionately higher $\mathrm{P}_{3}$ crown (fig. S16). It appears that there was a decrease of $\mathrm{P}_{3}$ size from the ancestral ape to Ar. ramidus conditions, but this reduction was greater in basal crown dimensions than in crown height (SOM text S1).

In Ar. ramidus, the combined effect of (i) reduced canine size and projection and (ii) reduced size and mesiobuccal extension of the $\mathrm{P}_{3}$ results in the absence of upper canine honing (defined as distolingual wear of the UC against the mesiobuccal $\mathrm{P}_{3}$ face, cutting into the lingual UC crown face and resulting in a sharpened distolabial enamel edge). Instead, apical wear in Ar. ramidus commences early and thereafter expands as wear progresses. None of the known UCs or $\mathrm{P}_{3} \mathrm{~s}$ exhibits evidence of honing (fig. S14). However, both upper and lower canines project beyond the postcanine occlusal plane before heavy wear, resulting in steep and beveled wear slopes, as also seen in examples of $A u$. afarensis and $A u$. anamensis $(1,4,20)$.

Two Ar. ramidus specimens provide associated maxillary and mandibular dentitions with minimal canine wear. One is almost certainly female $(A R A-V P-6 / 500)$, and the other is a probable male (ARA-VP-1/300) (see below). Both individuals possess a UC with a shorter crown height than the associated LC $(>10 \%$ difference in $A R A-V P-1 / 300)$ (21). In contrast in most anthropoid species, the UC is greater in height than the LC (fig. S17), a condition exaggerated in males of dimorphic species (over $50 \%$ in some papionins). Although less extreme in extant great apes (22), the UC still exceeds LC crown height by up to $20 \%$ (fig. S18). In modest samples of modern great ape canines with little to no wear, we found no instances of LC height exceeding that of the UC (25 males and 27 females). This pattern of relative UC and LC height in Ar. ramidus appears unique among anthropoids and indicates differential reduction 
of the UC in hominids. The UC $<$ LC height relation is retained in modern humans.

Morphological changes in the series $A r$. kadabba-Ar. ramidus-early Australopithecus support the hypothesis of selection-induced UC reduction. As detailed above, the UC is clearly derived in Ar. ramidus, whereas the LC tends to retain the primitive female apelike condition. $A u$. anamensis, geologically younger than $\mathrm{Ar}$. ramidus but older than $\mathrm{Au}$. afarensis, exhibits a polymorphic condition represented by both primitive and advanced LC morphologies $(4,20)$ (SOM text S1). The more incisiform morphology becomes universal in Au. afarensis and later hominids. Furthermore, compared with both male and female apes, Ar. ramidus exhibits a small UC crown (both basal diameter and height) relative to apico-cervical root length, more so than the LC (figs. S19 and S20). This observation provides further support to the interpretation that the UC crown was differentially reduced (SOM text $\mathrm{S} 1$ ).

A broader comparison of Ar. ramidus with extant and Miocene apes illuminates aspects of $\mathrm{C} / \mathrm{P}_{3}$ complex evolution. Compared with cercopithecoids, hominoids tend to have smaller $\mathrm{P}_{3} \mathrm{~s}$ with less extensive honing (fig. S15). Compared with other modern and Miocene apes, both species of $P$ an appear to show $\mathrm{P}_{3}$ reduction. The $\mathrm{P}_{3}$ of Ar. ramidus is even smaller, suggesting further reduction of the $\mathrm{C} / \mathrm{P}_{3}$ complex from an ancestral ape condition. At first sight, the comparatively small $\mathrm{P}_{3}$ size in Pan appears paradoxical, because among the modern great apes both male and female $P$. troglodytes have relatively large and tall canines (figs. S9 and S10 and SOM text $\mathrm{S} 1)$. However, this apparent paradox is removed by a broader perspective on tooth and body size proportions. Both Pan species share with atelines and Presbytis (sensu stricto) small postcanine size relative to body size (Fig. 2, figs. S21 and S22, and SOM text S2), low postcanine dimorphism, and low to moderate canine size dimorphism (figs. S23 to S25). Conversely, papionins exhibit the opposite condition: large postcanines, large canines, and extreme dimorphism. We therefore hypothesize that the basal Pan condition was characterized by a somewhat reduced $\mathrm{C} / \mathrm{P}_{3}$ complex as part of a generally small dentition relative to body size and that the canines were secondarily enhanced leading to modern $P$. troglodytes.

The ARA-VP-6/500 skeleton and sexual dimorphism. Of the 21 individuals with canines, $A R A-V P-6 / 500$ has UC and LC that are strikingly small; its UC ranks either 12th or 13th (of 13), and its LC ranks seventh (of eight) in size (table S6). However, postcranially, ARA-VP-6/ 500 is a large individual with an estimated body weight of $\sim 50 \mathrm{~kg}$ (23). Was $A R A-V P-6 / 500 \mathrm{a}$ small-canined male or a large-bodied female?

We began our evaluation of $A R A-V P-6 / 500$ (24) by estimating the degree of dimorphism in the Ar. ramidus canine (SOM text $\mathrm{S} 3$ ). Even in modern humans, the canine is metrically the most dimorphic tooth. Mean basal crown diameter of human male canines is about 4 to $9 \%$ larger than that in females (table S5). Our analysis indicates that Ar. ramidus was probably only marginally more dimorphic than modern humans (tables S6 to $\mathrm{S} 9$ and SOM text $\mathrm{S} 3$ ), with a probable range of 10 to $15 \%$ dimorphism (in canine mean crown diameter). This is substantially less dimorphic than modern great apes, whose male canines (mean crown diameter) are larger than those of females by 19 to $47 \%$.

On the basis of the above dimorphism estimate, the probability of a male having canines as small as those of $A R A-V P-6 / 500$ can be evaluated by bootstrapping (2). Assuming $12 \%$ dimorphism in mean canine size (table S8), the probability that $A R A-V P-6 / 500$ is a male is $<0.03$ (if the UC is ranked 12th of 13) or $<0.005$ (if ranked 13th) (table S9 and SOM text S4). We conclude that $A R A-V P-6 / 500$ is a large-bodied female, a conclusion also corroborated by cranial anatomy (25). This shows that skeletal size dimorphism in Ar. ramidus must have been slight (11), as is the case in both species of Pan $(26,27)$.

The $A R A-V P-6 / 500$ skeleton and dimorphism estimates allow us to place the Ar. ramidus dentition within a broader comparative framework. Scaling analyses (2) show that the UC of $A r$. ramidus was relatively small in both sexes (fig. S22 and SOM text S2). In particular, male UC height of Ar. ramidus is estimated to be close to that of female P. paniscus and Brachyteles and to be much lower than that of male $P$. paniscus (which has the least projecting male canine among extant catarrhines) (Fig. 2).

Canine development and function. In cercopithecoids with highly dimorphic canines, canine eruption is typically delayed in males, beginning after the age of eruption in females (28) and apparently corresponding with species-specific patterns of body size growth spurts (29-31). Once male canine eruption is initiated, it then proceeds at a higher rate than in females, but it can still last for several years depending on species (31). As a consequence, males attain full canine eruption as they approach or achieve adult body size, both of which are necessary for reproductive success (19).

Sexually distinct patterns of canine eruption in relation to body size growth have yet to be well documented in modern great apes but appear to broadly share the cercopithecoid pattern described above $(28,32-34)$. Initiation of canine eruption in $P$. troglodytes differs by about 1.5 to 2 years between the sexes (35). In males of both $P$. troglodytes and P. paniscus, full canine eruption appears to coincide broadly with M3 eruption (observations of skeletal materials), with polymorphism in the eruption sequence of the two teeth. By contrast in females of both species, full canine eruption is attained before M3 eruption.

Fig. 2. Size and scaling of the Ardipithecus ramidus dentition. Natural log-log scatter diagram of relative upper canine height (y axis) against relative postcanine length ( $x$ axis): left, females; right, males. Both axes represent size free variables (residuals) derived from scaling tooth size against body size across a wide range of anthropoids (2). A value of zero represents the average female catarrhine condition. Positive and negative residuals represent relatively large and small tooth sizes, respectively. The
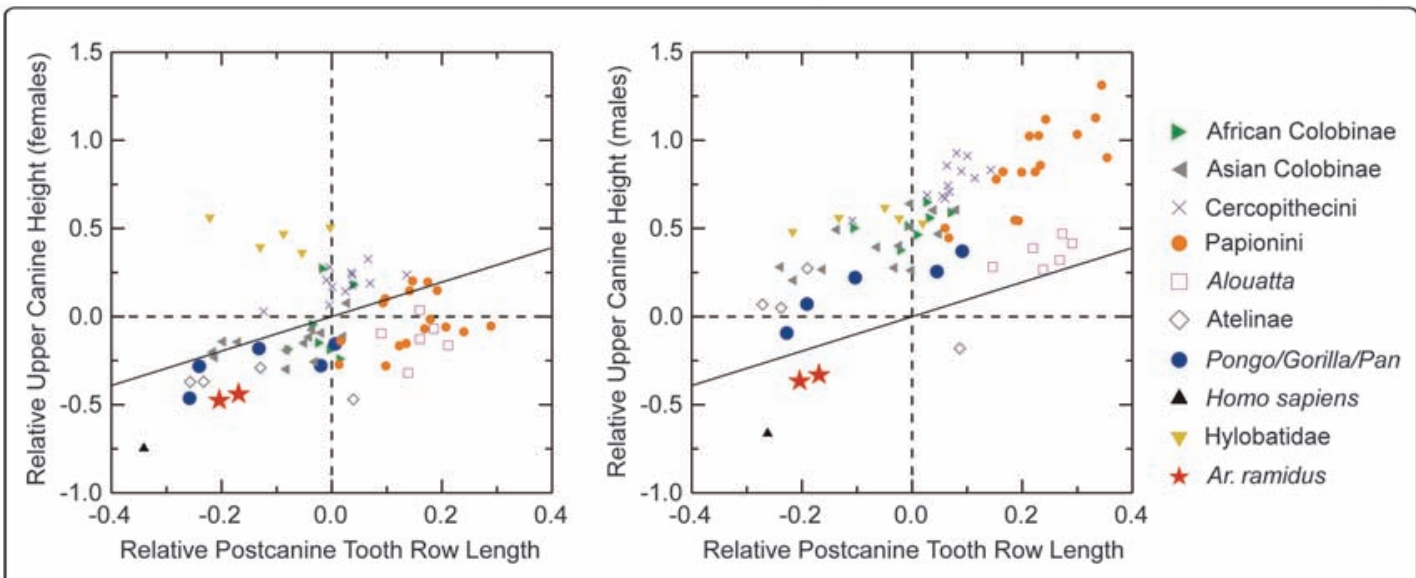
diagonal line indicates the di-

rection of equivalent canine and postcanine proportions independent of size. The five great ape taxa plotted are from left to right: $P$. paniscus, $P$. t. troglodytes, P. t. schweinfurthi, Gorilla gorilla, and Pongo pygmaeus. Ar. ramidus is plotted by using mean postcanine size and canine crown heights of probable female (ARA-VP-6/500) and male (ARA-VP-1/300) individuals. A hypothetical female body weight of $45 \mathrm{~kg}$ or $50 \mathrm{~kg}$ was used (right and left stars, respectively). Ar. ramidus is shown to have small postcanine tooth sizes, similar to those of Ateles, Presbytis sensu stricto, and Pan. Relative canine height of Ar. ramidus is lower than that of the smallest-canined nonhuman anthropoids, $P$. paniscus and Brachyteles arachnoides. See SOM text S2 for further details. 
The relative timing of canine eruption in $A r$. ramidus is revealed by two juveniles. The $A R A$ $V P-6 / 1$ holotype, a probable male (table $\mathrm{S} 6$ ), includes an unworn UC whose perikymata count is 193, higher than that in Au. africanus/afarensis (maximum 134, $n=4$ ) (36) and lower than those in small samples of female $P$. troglodytes and Gorilla (minimum 204, $n=10$ ) (37). The $A R A$ $V P-6 / 1$ UC crown formation time was 4.29 or 4.82 years, depending on estimates of enamel formation periodicity (fig. S26). This is a comparatively short formation time, around the minimum reported for modern female apes (38).

The eruption pattern of a second individual, $A R A-V P-1 / 300$, can be assessed from the presence or absence of wear facets and/or polish. The $A R A-V P-1 / 300$ canines were just completing eruption, its M2s were worn occlusally, and its unerupted M3 crowns were barely complete (Fig. 1 and fig. S27). Compared with extant apes, both its UC and LC development are advanced relative to M2 and M3 (fig. S28) (39).

The combined morphological and developmental evidence suggests that selection for delayed canine eruption had been relaxed in $\mathrm{Ar}$. ramidus. We hypothesize that canine prominence had ceased to function as an important visual signal in male competitive contexts.

Tooth size and diet. We consider relative incisor and postcanine sizes to be potentially useful in inferring dietary adaptations, although consistent patterns across primates have not been obtained (40). In particular, postcanine megadontia has been considered a defining feature of Australopithecus (41). We evaluated incisor and molar sizes of Ar. ramidus in comparison to those of Pan and Australopithecus. Among anthropoids, Pan and Pongo are unique in having large incisors relative to both postcanine and body size, a condition not shared by Ar. ramidus (fig. S29). This suggests that Ar. ramidus was not as inten- sive a frugivore as are Pan and Pongo, incisor length probably being functionally related to removal of fruit exocarp (42) and/or feeding behavior such as wadging.

Although the M1 area, normalized by individual postcranial metrics, lies well within the range of extant chimpanzees, the total postcanine area of $A R A-V P-6 / 500$ falls between Pongo and $P$. troglodytes (Fig. 3). Ar. ramidus is not only less megadont than Pongo and Au. afarensis but, together with Pan, Ateles, and some Presbytis species, lies at the small end of the range of variation of large-bodied anthropoids (fig. S30). The most megadont anthropoids include robust Australopithecus, such as Au. boisei, as well as papionins and Alouatta. Ouranopithecus was probably as megadont as Australopithecus species, whereas Dryopithecus and Pierolapithecus probably had relative postcanine sizes closer to Ar. ramidus and thus better approximate the dentition-to-body size relationship of the last common ancestor of humans and chimpanzees. We conclude that Ar. ramidus was substantially less megadont than Australopithecus.

Molar structure and enamel thickness. Molar structure, enamel thickness, and tooth wear further illuminate dietary adaptation in Ar. ramidus. Compared with the distinct occlusal structure of the molars of each of the modern ape species (see below), Ardipithecus occlusal morphology is more generalized, with low, bunodont cusps and moderate to strong basal crown flare. Such morphology also characterizes Australopithecus as well as a diversity of Miocene apes (43). Gorilla molars have much more salient occlusal topography and enhanced shearing crests. Pan molars are characterized by broad, capacious occlusal basins flanked by moderately tall cusps, effective in crushing relatively soft, fluidal mesocarp while retaining the ability to process more fibrous herbaceous materials (Fig. 4) (44, 45). These features are ac-
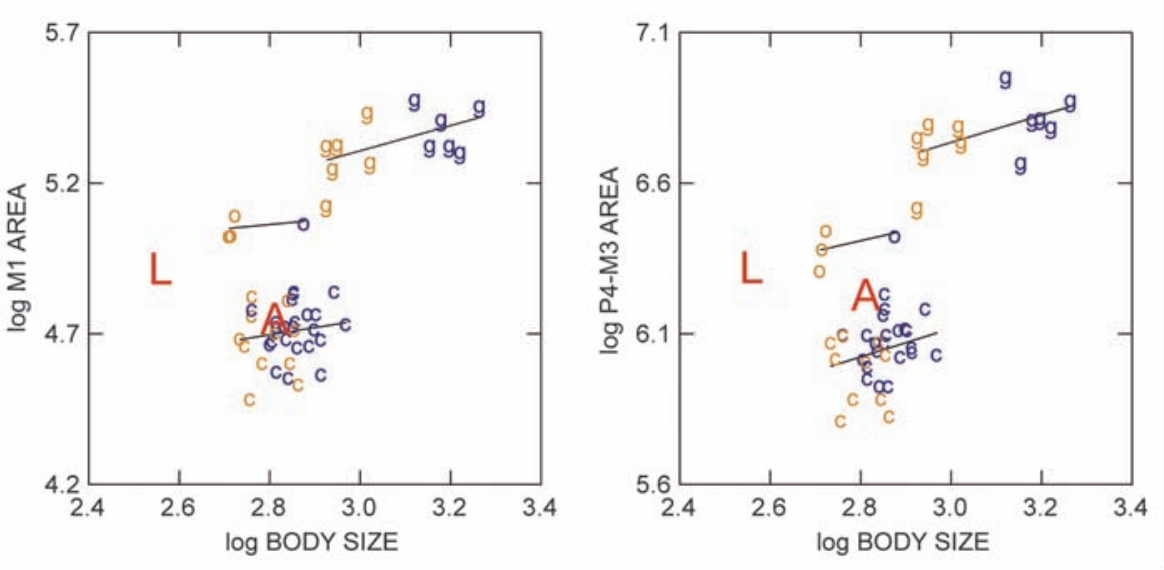

Fig. 3. Relative postcanine dental size in Ar. ramidus. Postcanine size is compared directly in reference to associated postcranial elements; $x$ axis is natural log of the size variable (body size proxy) of Lovejoy et al. (23), derived from four metrics of the talus and five metrics of the capitate; $y$ axis is natural log of the square root of the sum of calculated areas (mesiodistal length multiplied by buccolingual breadth) of lower $\mathrm{M}_{1}$ (left) and lower $\mathrm{P}_{4}$ to $\mathrm{M}_{3}$ (right). A, Ar. ramidus ARA-VP-6/500; L, Au. afarensis A.L. 288-1; c, Pan troglodytes troglodytes; g, Gorilla gorilla gorilla; 0, Pongo pygmaeus (males blue, females red). centuated in Pan by the characteristically thin enamel of its occlusal basin $(45,46)$.

To further elucidate molar structure and dietary adaptations of $\mathrm{Ar}$. ramidus, particularly in comparison with Pan and Australopithecus, we used micro-computed tomography (micro-CT) to study molar enamel thickness and underlying crown structures (2). Although the weak contrast of fossil enamel and dentin makes micro-CTbased evaluations difficult, we were able to assess several Ar ramidus molars with this method. These and analyses of CT sections and natural fracture data (2) indicate that Ar. ramidus enamel is considerably thinner than that of Australopithecus but not as thin as in Pan [as originally reported in (1)] (Fig. 4 and figs. S31 and S32).

Of particular importance is that Ar. ramidus molars do not exhibit enamel distribution patterns characteristic of $P$. troglodytes and P. paniscus. Both Pan species have similar crown structure and enamel distribution patterns (Fig. 4), although $P$. paniscus molars exhibit a higher cuspal topography, perhaps related to greater reliance on fibrous food $(46,47)$. Ar. ramidus lacks the thin occlusal fovea enamel of Pan and in this regard is similar to both Australopithecus and Miocene forms such as Dryopithecus (Fig. 4). The Pan condition is most likely derived, probably associated with an increased reliance on highercanopy ripe fruit feeding.

Despite the generalized molar structure common to both Ar. ramidus and Australopithecus, the adaptive difference between the two is expressed by enamel tissue volume, which we consider to broadly track net resistance to abrasion. Modern ape species exhibit a near-isometric relation between molar durability (measured as volume of enamel tissue available for wear per unit occlusal area) and tooth size, despite diverse dietary preferences and crown anatomy (Fig. 4). Ar. ramidus falls near this isometric continuum, but Australopithecus does not. Australopithecus molars achieve greater functional durability from increased enamel volume. Au. boisei occupies an extreme position distant from the modern ape baseline. Thus, both tooth size and enamel thickness and volume suggest a substantial adaptive shift from Ardipithecus to Australopithecus.

This is further expressed in molar macroand microscopic wear patterns. In contrast to Australopithecus, Ar. ramidus molars did not wear flat but instead retained stronger buccolingual wear slopes. The Aramis Ar. ramidus dentition also exhibits consistently weak M1 to M3 wear gradients (48). Microwear of the $A r$. ramidus molars tends to differ from that of $A u$. afarensis, the latter characterized by a dominance of buccolingually oriented scratches (49). In contrast, the Ar. ramidus molars tend to exhibit finer and more randomly oriented striae (fig. S33). Collectively, the wear evidence suggests that Ar. ramidus consumed a less abrasive diet and engaged in less masticatory grinding than Australopithecus. 
Enamel thickness and phylogenetic implications. Since the initial description of Ar. ramidus as a new species of Hominidae (1), its relatively thin molar enamel has been a focus of attention. Some authors have suggested that its thin enamel might be a shared derived feature with Pan (7). The fuller study of molar enamel thickness and patterns outlined above establishes the following: (i) Although Ar. ramidus enamel is thinner than that of Australopithecus, it is not as thin as Pan's; (ii) the thin enamel of Pan molars can be considered a part of a structural adaptation to ripe fruit frugivory (46) and therefore differs from the Ar. ramidus condition. Furthermore, the distinct internal structure of Pan molars seems lacking in Ar. kadabba, O. tugenensis, and $S$. tchadensis $(4,8,10)$. Hence, the Pan condition is best considered derived relative to the ancestral and early hominid conditions.

Conclusions. Multiple lines of morphological evidence suggest that Ar. ramidus was a generalized omnivore and frugivore that did not rely heavily on either ripe fruits (as in Pan or Pongo), fibrous plant foods (as in Gorilla), or hard and
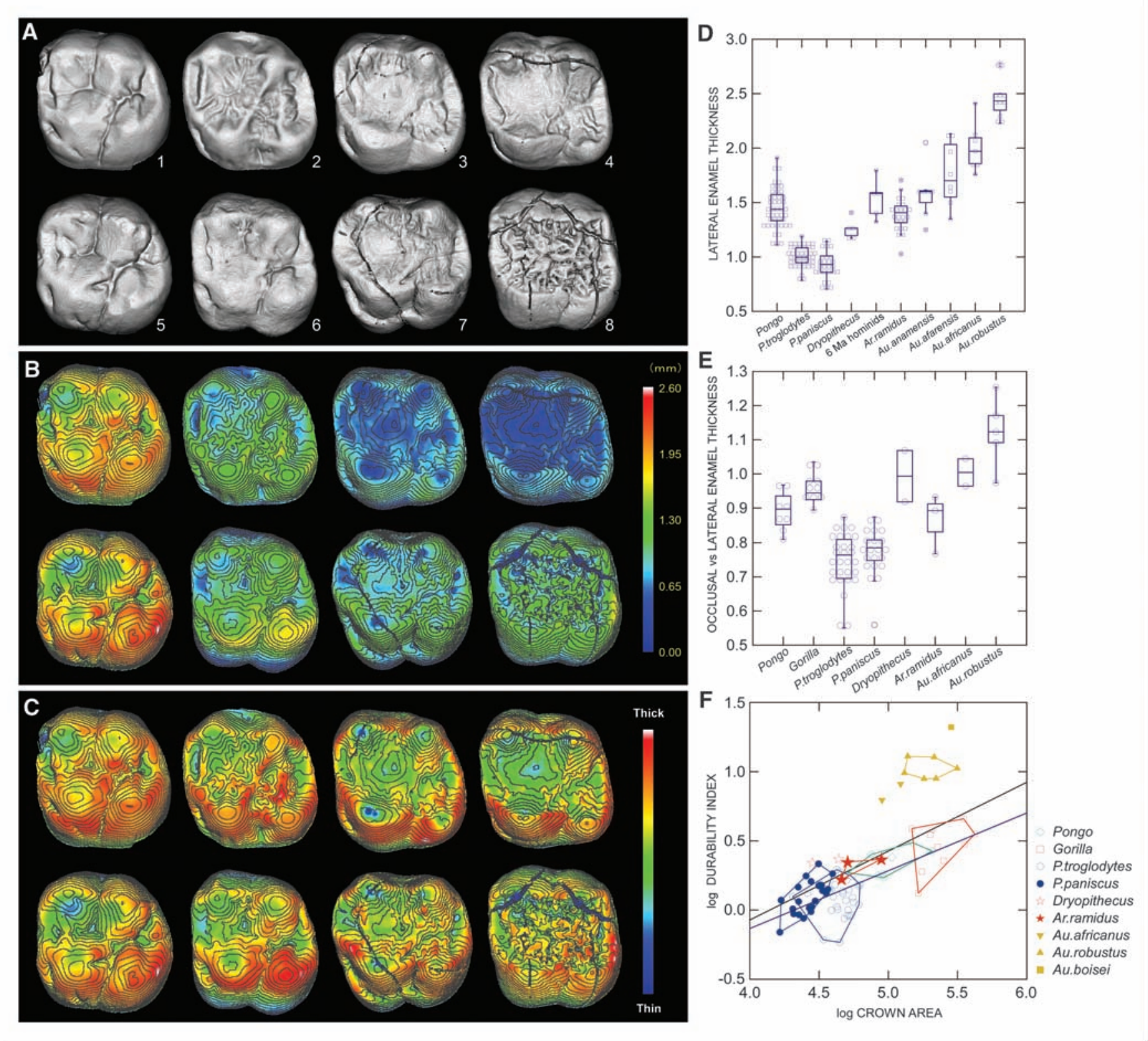

Fig. 4. Enamel thickness and distribution patterns in Ar. ramidus. Left panels: micro-CT-based visualizations of maxillary first molars in arbitrary size. (A) Outer enamel surface; (B) enamel thickness in absolute thickness scale superimposed on topographic contours; (C) enamel thickness in relative scale to facilitate comparison of pattern. The molars [labeled in (A)] are as follows: 1 and 5, Au. africanus Sts 24 (mirrored) and Sts 57; 2, Dryopithecus brancoi; 6, Ar. ramidus ARA-VP-1/3288; 3, Pan troglodytes; 4, Pan paniscus; 7, Gorilla gorilla; 8, Pongo pygmaeus. The Pan species share a broad occlusal basin and thin occlusal enamel. Both Ar. ramidus and $D$. brancoi are thinner-enameled than Australopithecus but share with Australopithecus a generalized distribution pattern. (D) Maximum lateral enamel thickness, showing that Ar. ramidus enamel is thicker than those of
Pan and D. brancoi and thinner than that of Australopithecus species. Horizontal line is median; box margins are central $50 \%$ range. (E) Ratio of occlusal (volume/surface area) to lateral (average linear) enamel thicknesses, showing that Pan is unique in its distinctly thin occlusal enamel. (F) Molar durability (enamel volume per unit occlusal view crown area) plotted against projected occlusal view crown area. An isometric line (slope of 0.5 ) is fitted through the centroid of the three measured Ar. ramidus molars. The least squares regression $(y=0.418 x-1.806)$ of the combined modern ape sample is also shown. This slope does not differ significantly from isometry. Ar. ramidus and D. brancoi are close to, and Australopithecus species considerably above, the regression line, indicating greater enamel volume available for wear in Australopithecus molars. See (2) for further details. 
tough food items (as in Pongo or Australopithecus). Ar. ramidus also lacked adaptations to abrasive feeding environments (unlike Australopithecus). These inferences are corroborated by the isotopic analysis of enamel, which indicates that Ar. ramidus predominantly consumed ( $\sim 85$ to $90 \%) \mathrm{C}_{3}$ plant sources in woodland habitats and small patches of forest (50), thus differing from both savanna woodland-dwelling chimpanzees $\left(>90 \% \mathrm{C}_{3}\right)$ and Australopithecus spp. (>30\% $\left.\mathrm{C}_{4}\right)(51)$.

Conversely, extant Pan and Gorilla, each with its distinctive dental morphology, are best considered derived in their dietary and dental adaptations. This is consistent with the Ar. ramidus postcranial evidence and its interpretations $(11,23)$ and strengthens the hypothesis that dental and locomotor specializations evolved independently in each extant great ape genus. This implies that considerable adaptive novelty was necessary to escape extinction in the Late Miocene forest and woodland environments.

These analyses also inform the social behavior of Ar ramidus and its ancestors. The dental evidence leads to the hypothesis that the last common ancestors of African apes and hominids were characterized by relatively low levels of canine, postcanine, and body size dimorphism. These were probably the anatomical correlates of comparatively weak amounts of male-male competition, perhaps associated with male philopatry and a tendency for male-female codominance as seen in P. paniscus and ateline species $(52,53)$.

From this ancestral condition, we hypothesize that the $P$. troglodytes lineage secondarily enhanced its canine weaponry in both sexes, whereas a general size reduction of the dentition and cranium (25) occurred in the $P$. paniscus lineage. This suggests that the excessively aggressive intermale and intergroup behavior seen in modern P. troglodytes is unique to that lineage and that this derived condition compromises the living chimpanzee as a behavioral model for the ancestral hominid condition. The same may be the case with Gorilla, whose social system may be a part of an adaptation involving large body size, a specialized diet, and marked sexual dimorphism.

In the hominid precursors of Ar. ramidus, the predominant and cardinal evolutionary innovations of the dentition were reduction of male canine size and minimization of its visual prominence. The Ar. ramidus dental evidence suggests that this occurred as a consequence of selection for a less projecting and threatening male upper canine. The fossils now available suggest that male canine reduction was well underway by 6 million years ago and continued into the Pliocene. Further fossils will illuminate the tempo and mode of evolution before 6 million years ago.

\section{References and Notes}

1. T. D. White, G. Suwa, B. Asfaw, Nature 371, 306 (1994)

2. Materials and methods are available as supporting material on Science Online.

3. S. Semaw et al., Nature 433, 301 (2005)

4. Y. Haile-Selassie, G. Suwa, T. D. White, in Ardipithecus kadabba: Late Miocene Evidence from the Middle Awash
Valley, Y. Haile-Selassie, G. WoldeGabriel, Eds. (Univ. California Press, Berkeley, 2009), pp. 159-236.

5. Y. Haile-Selassie, Nature 412, 178 (2001).

6. Y. Haile-Selassie, G. Suwa, T. D. White, Science $\mathbf{3 0 3}$, 1503 (2004).

7. B. Senut et al., C. R. Acad. Sci. Paris 332, 137 (2001)

8. M. Pickford, B. Senut, Anthropol. Sci. 113, 95 (2005).

9. M. Brunet et al., Nature 418, 145 (2002).

10. M. Brunet et al., Nature 434, 752 (2005).

11. T. D. White et al., Science 326, 64 (2009).

12. P. D. Gingerich, M. J. Schoeninger, Am. J. Phys. Anthropol. 51, 457 (1979).

13. D. A. Cope, in Species, Species Concepts, and Primate Evolution, W. H. Kimbel, L. B. Martin, Eds. (Plenum, New York, 1993), pp. 211-237.

14. J. M. Plavcan, thesis, Duke University (1990).

15. Mean postcanine size in one of two subspecies of the common chimpanzee that we examined $(P$. troglodytes schweinfurthi) is marginally greater in females. Pan paniscus and $P$. troglodytes both have postcanine teeth with size dimorphism weaker than in modern humans (table S5).

16. D. C. Johanson, thesis, Univ. of Chicago (1974)

17. W. G. Kinzey, in The Pygmy Chimpanzee: Evolutionary Biology and Behavior, R. L. Susman, Ed. (Plenum, New York, 1984), pp. 65-88.

18. Premolar root number and morphologies are known to be polymorphic, with single rooted $\mathrm{P}_{4} \mathrm{~s}$ known in both $\mathrm{Au}$. anamensis (KNM-ER 22683) and Au. afarensis (MAK-VP-1/12) $(54,55)$.

19. S. R. Leigh, ]. M. Setchell, M. Charpentier, L. A. Knapp, E. J. Wickings, J. Hum. Evol. 55, 75 (2008)

20. T. D. White et al., Nature 440, 883 (2006).

21. ARA-VP-1/300 UC and LC heights are 14.5 and $16.6 \mathrm{~mm}$, respectively. Reasonable estimates of crown height of the ARA-VP-6/500 UC and LC are 13 to $13.5 \mathrm{~mm}$ and $14.4 \mathrm{~mm}$, respectively.

22. J. Kelley, Am. J. Phys. Anthropol. 96, 365 (1995).

23. C. O. Lovejoy, G. Suwa, S. W. Simpson, ]. Matternes, T. D. White, Science 326, 73 (2009)

24. Our analysis for determining ARA-VP-6/500 sex consists of several steps detailed in (2) and SOM text S3. Although Ar. ramidus canines for which standard crown dimensions could be measured are limited, by comparing preserved portions, almost all can be ranked in terms of size. We therefore simulated probabilities of obtaining size ranks in model populations with set amounts of dimorphism in basal crown diameters.

25. G. Suwa et al., Science 326, 68 (2009).

26. P. L. Reno, R. S. Meindl, M. A. McCollum, C. O. Lovejoy, Proc. Natl. Acad. Sci. U.S.A. 100, 9404 (2003).

27. H. M. McHenry, Hum. Evol. 1, 149 (1986).

28. B. H. Smith, T. L. Crummett, C. L. Brandt, Yearb. Phys. Anthropol. 37, 177 (1994).

29. S. R. Leigh, B. T. Shea, Am. J. Phys. Anthropol. 101, 455 (1996).

30. Y. Hamada, S. Hayakawa, ]. Suzuki, S. Ohkura, Primates 40, 439 (1999).

31. S. R. Leigh, J. M. Setchell, L. S. Buchanan, Am. J. Phys. Anthropol. 127, 296 (2005).

32. K. L. Kuykendall, Am. J. Phys. Anthropol. 99, 135 (1996).

33. S. R. Leigh, B. T. Shea, Am. J. Phys. Anthropol. 99, 43 (1996).

34. Y. Hamada, T. Udono, Am. J. Phys. Anthropol. 118, 268 (2002).

35. G. C. Conroy, C. J. Mahoney, Am. J. Phys. Anthropol. 86, 243 (1991)

36. M. C. Dean, D. J. Reid, in Dental Morphology 2001, A. Brook, Ed. (Sheffield Academic Press, Sheffield, UK, 2001), pp. 135-149.

37. M. C. Dean, D. J. Reid, Am. J. Phys. Anthropol. 116, 209 (2001).

38. G. T. Schwartz, C. Dean, Am. J. Phys. Anthropol. 115, 269 (2001).

39. S. W. Simpson, C. O. Lovejoy, R. S. Meindl, Am. J. Phys. Anthropol. 87, 29 (1992).

40. C. J. Vinyard, ]. Hanna, J. Hum. Evol. 49, 241 (2005).

41. H. M. McHenry, Am. J. Phys. Anthropol. 64, 297 (1984).

42. P. W. Lucas, P. J. Constantino, B. A. Wood, J. Anat. 212, 486 (2008)

43. Many Miocene apes generally considered more advanced than Proconsul have molars with less expansive cingular structures. Such species, when they simultaneously lack distinct modifications of occlusal structure, all exhibit a common bunodont hominoid molar morphology. Such Miocene apes with this largely generalized molar morphology include Griphopithecus, Kenyapithecus, Equatorius, Nacholapithecus, Chororapithecus, Nakalipithecus, Dryopithecus, Pierolapithecus, Sivapithecus, Ankarapithecus, and Ouranopithecus. Slight differences in central tendencies in overall crown shape, occlusal cresting, accessory cuspules, and enamel thickness are used to distinguish among some of these taxa, but individual variation is high and specific distinctions are not necessarily clear on a specimen-by-specimen basis. One feature that seems to separate Late Miocene hominids, Ar. ramidus, and Australopithecus sp., on the one hand, and the Middle and Late Miocene apes, on the other, is the lack of a well-developed and distinct protoconule in the upper molars of hominids. This condition is also shared by both genera of extant African apes and may be characteristic of the African ape and human clade.

44. E. Vogel et al., J. Hum. Evol. 55, 60 (2008).

45. R. T. Kono, Anthropol. Sci. 112, 121 (2004)

46. R. T. Kono, G. Suwa, Bull. Natl. Mus. Nat. Sci. Ser. D. 34 , 1 (2008).

47. R. K. Malenky, R. W. Wrangham, Am. J. Primatol. 32, 1 (1994).

48. Two of five available Ar. ramidus individual molar rows show comparable dentine exposure at all three molar positions. The remaining three individuals show either weak or no clear gradients between adjacent molar pairs. In contrast to Australopithecus, both Ar. ramidus and $\mathrm{Ar}$. kadabba molars exhibit deep dentine exposures suggestive of erosive rather than abrasive wear (4).

49. F. E. Grine, P. S. Ungar, M. F. Teaford, S. El-Zaatari, J. Hum. Evol. 51, 297 (2006).

50. T. D. White et al., Science 326, 67 (2009).

51. M. Sponheimer et al., J. Hum. Evol. 51, 128 (2006)

52. A. D. Di Fiore, R. C. Fleischer, Int. J. Primatol. 26, 1137 (2005).

53. C. J. Campbell, Ed., Spider Monkeys: Behavior, Ecology and Evolution of the Genus Ateles (Cambridge Univ. Press, Cambridge, 2008)

54. T. D. White, G. Suwa, S. Simpson, B. Asfaw, Am. J. Phys. Anthropol. 111, 45 (2000).

55. E. D. Shields, Am. J. Phys. Anthropol. 128, 299 (2005).

56. For funding, we thank NSF (grant nos. 8210897 9318698, 9512534, 9632389, 9727519, 9729060, 9910344, and 0321893 HOMINID-RHOI) and the Japan Society for the Promotion of Science (grant nos. 11640708, 11691176, 14540657, 16405016, 16770187, 17207017 19207019, 19770215, and 21255005); the Ministry of Tourism and Culture, the Authority for Research and Conservation of the Cultural Heritage, and the National Museum of Ethiopia for permissions and facilitation; the Afar Regional Government, the Afar people of the Middle Awash, and many other field workers for contributing directly to the data; the institutions and staff of National Museum of Ethiopia, National Museums of Kenya, Transvaal Museum South Africa, Cleveland Museum of Natural History, Royal Museum of Central Africa Tervuren, Naturalis Leiden, and the Department of Zoology of the National Museum of Nature and Science (Tokyo) for access to comparative materials; H. Gilbert for graphics work on Fig. 1; D. DeGusta and L. Hlusko for editorial assistance; R. Bernor, L. de Bonis, M. Brunet, M. C. Dean, B. Engesser, F. Guy, E. Heizmann, W. Liu, S. Moya-Sola, M. Plavcan, D. Reid, S. Semaw, and J. F. Thackeray for cooperation with comparative data and fossils; and T. Tanijiri, M. Chubachi, D. Kubo, S. Matsukawa M. Ozaki, H. Fukase, S. Mizushima, and A. Saso for analytical and graphics assistance.

\section{Supporting Online Material}

www.sciencemag.org/cgi/content/full/326/5949/69/DC1 Materials and Methods

SOM Text

Figs. S1 to S33

Tables $\mathrm{S1}$ to $\mathrm{S9}$

References

4 May 2009; accepted 18 August 2009

$10.1126 /$ science. 1175824 